\title{
Imiquimod//-Cyclodextrin Inclusion Complex: Experimental and Theoretical Studies
}

\author{
Luciana S. Guedes, ${ }^{\circledR a}$ Nelson H. Morgon, ${ }^{\circledR * a}{ }^{*}$ Milene H. Martins ${ }^{a}$ and \\ Francisco B. T. Pessine ${ }^{\circledR a}$ \\ ${ }^{a}$ Departamento de Físico-Química, Instituto de Química, Universidade Estadual de Campinas, \\ CP 6154, 13084-970 Campinas-SP, Brazil
}

\begin{abstract}
Imiquimod (IMQ), an immune response modifier, is used for topical treatment of basal cell carcinoma and actinic keratosis. The very poor aqueous solubility of imiquimod gives rise to difficulties in designing aqueous formulations with this drug. One approach that is widely used to enhance drug solubility is complexation with cyclodextrins. The formation of the inclusion complex between IMQ and $\beta$-cyclodextrin was investigated in solution and in solid state. IMQ aqueous solubility was improved in the presence of citric acid. The experimental results and molecular modeling indicated the formation of the inclusion complex in aqueous solution of citric acid $\mathrm{pH} 3.0$; however, the low apparent stability constant suggested weak interaction between $\beta$-cyclodextrin and IMQ which hampered the use of this approach to improve imiquimod aqueous solubility and the development of an aqueous formulation containing IMQ in the same concentration as in the commercial product.
\end{abstract}

Keywords: imiquimod, $\beta$-cyclodextrin, citric acid, inclusion complex, physicochemical characterization, molecular modeling

\section{Introduction}

Imiquimod (IMQ) is marketed by $3 \mathrm{M}$ Pharmaceuticals under the trade name Aldara. It is an immune response modifier and is indicated for topical treatment of external genital and perianal warts, basal cell carcinoma, Bowen's disease and actinic keratosis. ${ }^{1-4}$ IMQ (Figure 1a) is a weakly basic drug ( $\mathrm{p} K_{\mathrm{a}} 7.3$ at $22{ }^{\circ} \mathrm{C}$ ) whose solubility is strongly influenced by $\mathrm{pH}$ variations. It has a molecular weight of $240.30 \mathrm{Da}$ and high melting point $297-299{ }^{\circ} \mathrm{C}$. IMQ is practically insoluble in water $\left(0.60 \mu \mathrm{g} \mathrm{mL}^{-1}\right)$ and sparingly soluble in other common pharmaceutical solvents. ${ }^{5}$ The very poor aqueous solubility of IMQ gives rise to difficulties in the design of aqueous formulations with this drug. One approach that is widely used to enhance drug solubility is complexation with cyclodextrins.

Cyclodextrins are cyclic oligosaccharides consisting of $\alpha$-D-glucopyranose units linked by $\alpha-1,4$ bonds, with a hydrophobic inner cavity and hydrophilic outer surface (Figures $1 \mathrm{~b}$ and $1 \mathrm{c}$ ). The most abundant natural cyclodextrins are $\alpha$-cyclodextrin $(\alpha \mathrm{CD}), \beta$-cyclodextrin $(\beta C D)$ and $\gamma$-cyclodextrin $(\gamma \mathrm{CD})$ containing 6,7 and 8 glucopyranose units, respectively. Cyclodextrins take the

*e-mail: nhmorgon@unicamp.br shape of a truncated cone due to the chair conformation of the glucopyranose units and the hydroxyl functions are oriented to the exterior with the primary hydroxyl groups of the glucose residues at the narrow edge of the cone and the secondary hydroxyl groups at the wider edge..$^{6-10} \mathrm{An}$ important characteristic of cyclodextrins is their ability to form water-soluble inclusion complexes with hydrophobic drugs. No covalent bonds are formed or broken during drug-cyclodextrin complex formation and free drug molecules are in dynamic equilibrium with drug molecules in the complex. ${ }^{6,11}$ Even though cyclodextrins have been extensively studied as drug carriers, their complexation efficiency is rather low and a substantial amount of cyclodextrins is necessary to solubilize small amounts of the drug. ${ }^{12,13}$ One strategy to increase cyclodextrin solubilization capacity is the addition of suitable auxiliary substances. The addition of low molecular weight acids or hydroxyacids, e.g., citric acid (CA), tartaric acid, can both enhance cyclodextrin solubilization capacity and also improve drug solubility. Studies ${ }^{14-17}$ have shown a synergic effect between cyclodextrins and hydroxyacids on solubilization of poor basic drugs. Hydroxyacids do not have an affinity for the cyclodextrin cavity owing to the presence of hydrophilic moieties along their molecular backbone. As a result, they interact with the inclusion 
complex by both ion pairing and also through the formation of hydrogen bonds with hydroxyl groups located on the cyclodextrin exterior. $^{7}$

In the present work, we investigated the formation of $\beta C D$ :IMQ complex with the aim to increase IMQ solubility in water and develop an aqueous formulation containing IMQ at the same concentration as in the commercial product. The formation of inclusion complex was evaluated, in solution, by UV-Vis absorption spectroscopy and nuclear magnetic resonance (NMR). The physico-chemical properties of the solid complex were investigated by differential scanning calorimetry (DSC), powder X-ray diffractometry (PXRD) and scanning electron microscopy (SEM) in order to give insight on the complex formation. 1D-rotating-frame Overhauser (ROESY) NMR experiments and molecular modeling were employed to elucidate certain features of the inclusion complex. 1D-ROESY NMR experiments provided detailed description of $\beta C D$ :IMQ complex geometry while molecular modeling was used to identify the most probable conformation of the inclusion complex.

\section{Experimental}

Material

$\beta C D$ was purchased from ISP Technologies (Jandira, Brazil). IMQ was kindly supplied by EMS Sigma Pharma (Hortolândia, Brazil) and was of pharmaceutical grade. All other reagents and solvents were of analytical grade and used as received. The water used in all experiments was purified on a Milli-Q system (Millipore). The ${ }^{1} \mathrm{H}$ NMR measurements were carried out in deuterium oxide $\left(\mathrm{D}_{2} \mathrm{O}\right.$, Cambridge Isotope, Tewksbury, United States) or dimethyl sulfoxide (DMSO- $d_{6}$, Sigma-Aldrich, São Paulo, Brazil) solutions.

\section{Methods}

Preparation of physical mixtures

The 1:1 molar ratio of $\beta C D$ and IMQ ( $\beta C D$ :IMQ) or 1:1:1 molar ratio of $\mathrm{CA}, \beta \mathrm{CD}$ and IMQ (CA: $\beta C D: I M Q)$ physical mixtures were prepared by homogeneous mixing of previously weighted powders in a mortar with a spatula for $2 \mathrm{~min}$. The physical mixtures were used for analytical comparison with the drug-cyclodextrin solid complex.

\section{Preparation of drug-cyclodextrin solid complex}

The inclusion complex was prepared by mixing (at 1:1:1 molar ratio) CA, $\beta C D$ and IMQ. First, an amount of $500 \mathrm{mg}$ of $\beta C D$ was diluted in $92 \mathrm{~mL}$ of deionized water. Second, an amount of $85 \mathrm{mg}$ of CA was added to the solution. Next, an amount of $106 \mathrm{mg}$ of IMQ was added to the solution and left under stirring for $15 \mathrm{~min}$ at $25^{\circ} \mathrm{C}$. The solution was filtered through $0.45 \mu \mathrm{m}$ syringe filter (Millipore), frozen in liquid nitrogen and submitted to lyophilization for $72 \mathrm{~h}$ (Liotop, K105 model).

\section{Phase solubility studies}

The most used approach to study inclusion complexes is the shake-flask method established by Higuchi and Connors..$^{18}$ It is the first tool to study the formation of inclusion complexes in solution. The apparent stability constants $\left(\mathrm{K}_{1: 1}\right)$ were obtained from the phase solubility diagrams which also gave insight into the stoichiometry of the inclusion complex. ${ }^{18-21}$ Phase solubility study was carried out in acetate buffer $\mathrm{pH}$ 5.6, phosphate buffer $\mathrm{pH} 7.4$ and aqueous solution of citric acid $\mathrm{pH}$ 3.0. IMQ solubility was evaluated in the presence of increasing concentration of $\beta C D$. Excess amounts of IMQ $(10 \mathrm{mg})$ were added to $10 \mathrm{~mL}$ of the solutions containing increasing concentration of $\beta \mathrm{CD}$ (0 to $16 \mathrm{mM})$. It was used 1:1 molar ratio (CA:IMQ) for the study in aqueous solution of citric acid. The obtained suspensions were shaken at $25{ }^{\circ} \mathrm{C}$ for $24 \mathrm{~h}$. After equilibrium, aliquots were withdrawn, filtered through $0.45 \mu \mathrm{m}$ syringe filter (Millipore) and assayed spectrophotometrically (Varian, Cary 50) for IMQ content at $226 \mathrm{~nm}$. Each experiment was carried out in duplicate. Phase solubility diagrams were obtained by plotting the solubility of IMQ, in $\mathrm{mg} \mathrm{mL}^{-1}$, versus the concentration of $\beta C D$ used. From the phase solubility diagrams, the apparent stability constants $\left(\mathrm{K}_{1: 1}\right)$ were calculated from the equation 1 , where the slope is
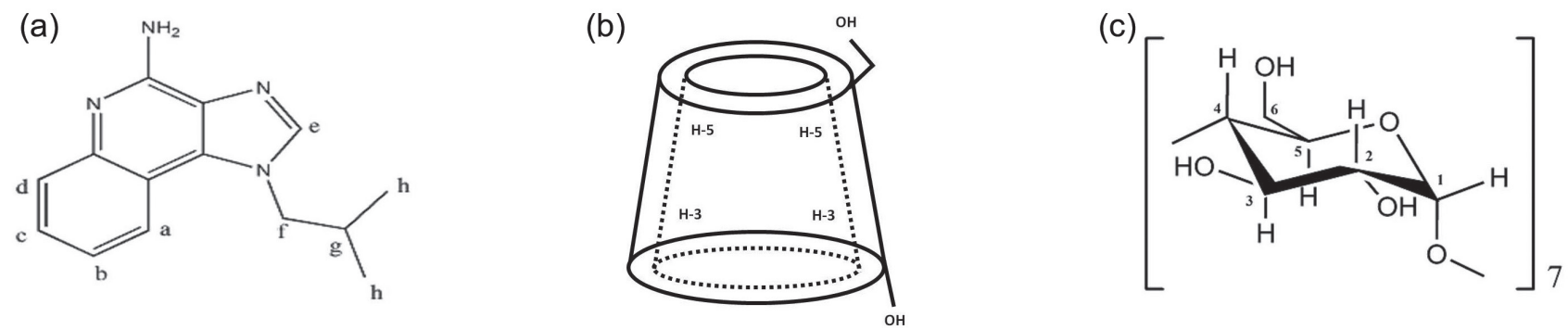

Figure 1. Molecular structure of imiquimod $\{1$-(2-methylpropyl)-1H-imidazo[4, 5-c]quinolin-4-amine $\}$ (a); $\beta C D$ (b); $\beta C D$ glucopyranose unit (c). 
the angular coefficient and $\mathrm{S}_{0}$ is the drug solubility in the absence of cyclodextrin.

$\mathrm{K}_{1: 1}=\frac{\text { slope }}{\left[\mathrm{S}_{0}(1-\text { slope })\right]}$

\section{Determination of complex stoichiometry}

To determine the complex stoichiometry, the method of continuous variation (Job's plot) was employed, based on the differences in the UV-Vis absorption of IMQ in the presence of $\beta C D, \Delta A=A_{I M Q}-A_{\beta C D: I M Q}$, where $A_{I M Q}$ represents UV-Vis absorption of IMQ in the absence of $\beta C D$ and $A_{\beta C D: I M Q}$ the UV-Vis absorption attributed to the IMQ in the presence of $\beta C D$. An IMQ solution at a concentration of $3.0 \mathrm{mM}$ was prepared in ethanol containing the same molar ratio of CA. A volume of $500 \mu \mathrm{L}$ of this solution was diluted in deionized water to obtain $50 \mathrm{~mL}$ of a solution at a concentration of $0.03 \mathrm{mM}$. A $\beta C D$ solution was prepared in deionized water at a concentration of $0.03 \mathrm{mM}$. Different volumes of each solution were added to the cuvette to have molar fractions of IMQ varying from 0 to 1.0 . The measurements were done in duplicate. The $\beta C D$ :IMQ complex stoichiometry was obtained by the Job's plot, where on the $y$ axis was plotted the absorption difference between the solution containing $\beta C D$ and IMQ and the solution containing free IMQ multiplied by IMQ molar fraction and on the $x$ axis was plotted IMQ molar fraction. The molar fraction of IMQ (R) corresponding to the maximum of the curve indicates the inclusion complex stoichiometry where $\mathrm{R}=\mathrm{m} /(\mathrm{m}+\mathrm{n})$ and $\mathrm{m}$ and $\mathrm{n}$ are the stoichiometric coefficients of IMQ and $\beta C D$ in the complex, respectively. ${ }^{22,23}$

\section{${ }^{1} \mathrm{H}$ NMR analyses}

NMR analyses were performed on a Bruker $400 \mathrm{MHz}$ Avance II spectrometer. Samples for ${ }^{1} \mathrm{H}$ and 1D-ROESY NMR experiments were prepared as follows: an appropriate amount of $\beta C D$, CA or $\beta C D$ :IMQ complex was dissolved in $\mathrm{D}_{2} \mathrm{O}$ and IMQ in DMSO- $d_{6}$. All compounds were at concentration of $26 \mathrm{mM}$. The chemical shift $(\delta)$ at $4.71 \mathrm{ppm}$ due to water traces in the solvent was used as internal reference, except for IMQ spectra that was referenced by DMSO- $d_{6}$ chemical shift. The parameters for ${ }^{1} \mathrm{H}$ NMR spectra were 64 scans, $1.992 \mathrm{~s}$ acquisition time and $1.0 \mathrm{~s}$ relaxation delay. The residual water signal was suppressed by pre-saturation during the recycling delay. 1D-ROESY NMR spectra were recorded using the standard pulse sequence of the equipment (selrogp.2) at $25{ }^{\circ} \mathrm{C}$. The acquisition parameters used were $32 \mathrm{k}$ data points, relaxation delay (d1) $5 \mathrm{~s}$, mixing time (p15) $400 \mathrm{~ms}$ and 512 increments. The 1D-ROESY data were processed with $3 \mathrm{~Hz}$ line-broadening (lb). IMQ resonance was assigned using 2D NMR correlation spectroscopy (COSY) spectra. The COSY spectrum was recorded using cosygpqf pulse program over a spectral width of $4 \mathrm{kHz}$, 1.0 s relaxation delay, 1024 points in F2 dimension and 256 points in $\mathrm{F} 1$ dimension. The spectrum was acquired with 2 transients for each of the 256 increments. ${ }^{1} \mathrm{H}, \mathrm{COSY}$ and 1D-ROESY NMR data were processed with Bruker TopSpin software.

Samples for diffusion-ordered spectroscopy (DOSY) experiments were prepared in $1 \mathrm{~mL}$ of $\mathrm{D}_{2} \mathrm{O}$. Amounts of $5 \mathrm{mg}$ of IMQ and $4 \mathrm{mg}$ of CA (1:1 molar ratio) were added to Eppendorf tubes containing increasing quantities of $\beta \mathrm{CD}(0,4,8,12,16 \mathrm{mM})$. After centrifugation (5 min, $14,000 \mathrm{rpm}$ ) the solutions were transferred to NMR tubes for analysis. DOSY experiments were carried out using oneshot pulse sequence. The following parameters were optimized before running the diffusion measurements: (i) diffusion time $(\Delta, \mathrm{d} 20), 60 \mathrm{~ms}$; (ii) diffusion gradient length ( $\delta$, p30), $1500 \mu \mathrm{s}$; (iii) recovery delay (d16), $200 \mu \mathrm{s}$; (iv) gradient strength $\mathrm{g}$, from 10 to $80 \%$ in 16 equivalent steps. DOSY data were analyzed with DOSY Toolbox software. ${ }^{24}$

\section{Differential scanning calorimetry (DSC)}

Thermal analyses of the individual components, physical mixtures or $\beta C D$ :IMQ complex were performed using differential scanning calorimetry (TA Instruments, 2910 model). Weighted samples (5-10 mg) were scanned in $\mathrm{Al}$ pans at $10{ }^{\circ} \mathrm{C} \mathrm{min}^{-1}$ under nitrogen atmosphere. The scans of IMQ, $\beta C D$ and $\beta C D$ :IMQ physical mixture were obtained in the range of $25-350{ }^{\circ} \mathrm{C}$ and the DSC curves of CA, CA: $\beta C D$ :IMQ physical mixture and $\beta C D$ :IMQ complex were obtained from 25 to $250{ }^{\circ} \mathrm{C}$.

\section{Powder X-ray diffractometry (PXRD)}

The PXRD diffraction patterns of individual CA, IMQ, $\beta C D$, physical mixtures and $\beta C D$ :IMQ complex were determined using the X-ray diffractometer (Shimadzu, DRX-6000). Samples were irradiated with Ni-filtered $\mathrm{Cu} \mathrm{K} \alpha$ radiation $(1.5406 \AA$ ), at $40 \mathrm{kV}$ voltage, $30 \mathrm{~mA}$ current, over a diffraction angle of $2 \theta$ and range of $5-50^{\circ}$.

\section{Scanning electron microscopy (SEM)}

The morphological features of the individual components, $\mathrm{CA}$ : $\beta \mathrm{CD}$ :IMQ physical mixture and inclusion complex were examined by SEM (JEOL, JSM-6360/LV). Samples were previously fixed on a stub using double-sided adhesive tape and coated in a vacuum with a thin layer of gold. Photomicrographs were taken at magnification factor from $100 \times$ to $1300 \times$. 


\section{Molecular modeling}

All calculations were performed in Gaussian 16, Revision A.03. ${ }^{25}$ The B3LYP method and the 6-31G(d) basis set were used to calculate vibrational frequencies and to perform geometry optimization for CA, citrate, IMQ and IMQ+. Solvation effects were included using the integral equation formalism-polarizable continuum model (IEF-PCM). The molecular structure of $\beta C D$ was obtained from $X$-ray diffraction. Inclusion complexes with optimized molecules were built employing traversing and rotating models. For traversing models, inclusion complexes were built by placing the guest molecule (CA, citrate, IMQ and $\left.\mathrm{IMQ}^{+}\right)$up to a distance of $5 \AA$ from $\beta \mathrm{CD}$ center of mass. Translational motions of the guest molecules were measured from both sides of $\beta C D$; measurements were carried out at each $0.1 \AA$ displacement. For rotating models, rotational motions of the guest molecules were measured at $30^{\circ}$ intervals; calculations were carried out at the semi-empirical PM6 method + IEF-PCM theory level. From the calculated energies, population analysis was performed considering Boltzmann distribution to select $20 \%$ of the complexes with lower energies. Additionally, UV-Vis electronic spectra for the selected complexes were calculated by the time-dependent density functional theory (TD-DFT) method. Solvation effects were included by using the IEF-PCM model. Calculations were performed by considering the two-layered ONIOM method. The CAM-B3LYP/6-311++G(3df,2p) method was used at the high level of theory while $\beta C D$ was described at the low level of theory by PM6. Fifteen electronic singlet states were obtained, and UV-Vis spectra were weighted by Boltzmann distribution factor. The thermodynamic parameters, i.e., the standard enthalpy change $(\Delta \mathrm{H})$, the standard entropy change $(\Delta S)$ and the standard free energy change $(\Delta G)$ were obtained from the geometry optimization and the harmonic vibrational frequencies. A full molecular optimization was performed on the system, $\beta C D$ and IMQ; in this approach $\beta C D$ molecule was kept flexible. Additionally, a geometry optimization was performed only on IMQ molecule while $\beta C D$ molecule was kept frozen. The thermal corrections were obtained at temperature $298.15 \mathrm{~K}$, pressure $1.013 \times 10^{5}$ Pascal employing the ideal gas model, rigid rotor and harmonic normal mode approximations. All frequencies were scaled by 1.00 .

\section{Results and Discussion}

\section{Phase solubility studies}

Phase solubility diagrams of IMQ in aqueous solution of citric acid $\mathrm{pH}$ 3.0, acetate buffer $\mathrm{pH} 5.6$ and phosphate buffer $\mathrm{pH} 7.4$ are shown in Figure 2. IMQ solubility increased linearly as function of $\beta C D$ concentration. In the range of $\beta C D$ concentration studied the phase solubility diagrams can be classified as $\mathrm{A}_{\mathrm{L}}$ type. The slopes of the diagrams were lower than one unit and in the absence of other information, the stoichiometry of the inclusion complex was assumed to be 1:1 even though the occurrence of higher order complexes was not excluded. ${ }^{9}$ From the phase solubility diagrams, it can be observed that the solubility of IMQ in aqueous solution of citric acid $\mathrm{pH} 3.0$ increased 4-fold when compared with its solubility in acetate buffer $\mathrm{pH} 5.6$ and 156-fold greater than the solubility in phosphate buffer $\mathrm{pH}$ 7.4. The solubility of a weak basic drug (IMQ $\mathrm{p} K_{\mathrm{a}}$ is 7.3$)^{5}$ increases exponentially with decreasing $\mathrm{pH}$ below its $\mathrm{p} K_{\mathrm{a}}{ }^{26}$

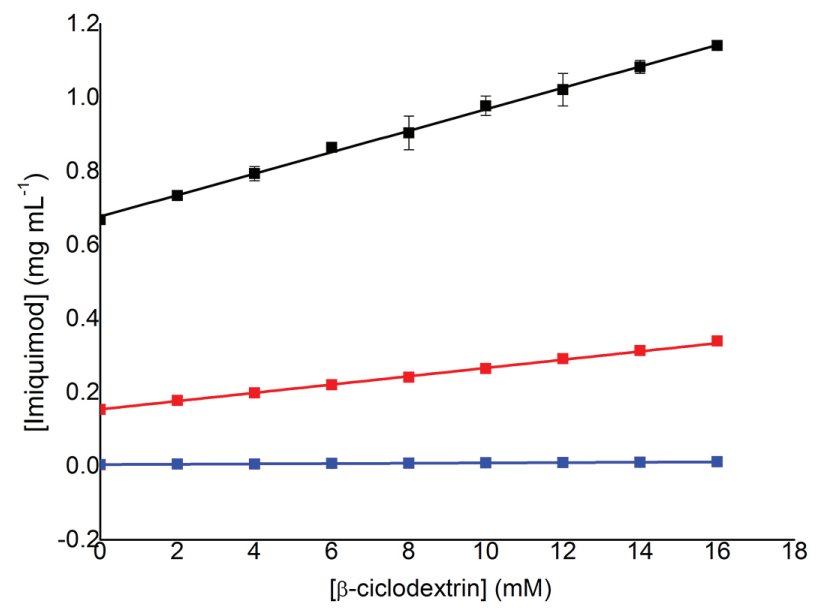

Figure 2. Phase solubility diagrams of IMQ in aqueous solution of citric acid pH 3.0 (black), acetate buffer pH 5.6 (red) and phosphate buffer $\mathrm{pH} 7.4$ (blue) at $25^{\circ} \mathrm{C}$.

The simultaneous formation of inclusion complex and salt is employed to improve the solubility of poor soluble drugs. ${ }^{15,16}$ The addition of hydroxyacids like CA increases the solubilizing effect of cyclodextrin on basic drugs as a result of salt and complex formation. ${ }^{13}$ The results suggested that $C A$ and $\beta C D$ have a synergic effect on IMQ solubility and demonstrated that the inclusion complex solubility is superior to the complex obtained by $\mathrm{pH}$ adjustment. ${ }^{27}$ When present in high concentration, hydroxyacids increase the solubility of the guest molecule. The increase in $\beta C D$ solubility can be associated to both changes in the intramolecular hydrogen bonds involving $\beta C D$ secondary hydroxyl groups and also to changes in the interactions with water molecules. ${ }^{26}$ Table 1 shows IMQ solubility in the studied media, in the absence and presence of $\beta C D 16 \mathrm{mM}$, the relative increment (R.I.) of its solubility, the apparent stability constant $\left(\mathrm{K}_{1: 1}\right)$ and the complexation efficiency (C.E.) at $226 \mathrm{~nm}$. 
Table 1. IMQ aqueous solubility in the absence and presence of $\beta C D 16 \mathrm{mM}$, the relative increment of drug solubility, the apparent stability constant and the complexation efficiency (between brackets the standard deviation)

\begin{tabular}{lccccc}
\hline Media & $\mathrm{IMQ}^{\mathrm{a}} /\left(\mathrm{mg} \mathrm{mL}^{-1}\right)$ & $\beta \mathrm{CD}: \mathrm{IMQ}^{\mathrm{b}} /\left(\mathrm{mg} \mathrm{mL}^{-1}\right)$ & ${\text { R.I. }{ }^{\mathrm{c}}}$ & $\mathrm{K}_{1: 1}{ }^{\mathrm{d}} / \mathrm{M}^{-1}$ & C.E. $^{\mathrm{e}}$ \\
\hline Aqueous solution of citric acid pH 3.0 & $0.669( \pm 0.012)$ & $1.141( \pm 0.006)$ & 1.7 & $50.66( \pm 1.13)$ & 0.141 \\
Acetate buffer pH 5.6 & $0.153( \pm 0.004)$ & $0.339( \pm 0.005)$ & 2.2 & $76.54( \pm 1.11)$ & 0.048 \\
Phosphate buffer pH 7.4 & $0.004(<0.001)$ & $0.012(<0.001)$ & 2.7 & $109.13( \pm 0.03)$ & 0.002 \\
\hline
\end{tabular}

IMQ: aqueous solubility of the free drug (imiquimod); ${ }^{\mathrm{b}} \beta \mathrm{CD}$ :IMQ: IMQ aqueous solubility in the presence of $\beta$-cyclodextrin $(\beta C D)$; ${ }^{\mathrm{c}} \mathrm{R} . \mathrm{I} .:$ ratio between IMQ aqueous solubility in the presence of $\beta C D$ and the free drug; ${ }^{d} K_{1: 1}$ : apparent stability constant; ${ }^{e} C . E .: K_{1: 1} S_{0}$, where $S_{0}$ is in $M$.

The results were evaluated in terms of apparent stability constant and complexation efficiency. Additionally, it was considered the presence of neutral and protonated forms of IMQ in solution. Figure 3 shows a schematic representation of the association-dissociation equilibrium of the inclusion complex considering 1:1 stoichiometry where IMQ and IMQ ${ }^{+}$are the neutral and protonated forms of IMQ, respectively, $\beta C D$ is beta-cyclodextrin, IMQ- $\beta C D$ and $\mathrm{IMQ}^{+}-\beta \mathrm{CD}$ are the inclusion complexes formed between $\beta C D$ and the neutral and protonated forms of IMQ, respectively, $\mathrm{K}_{1: 1}$ and $\mathrm{K}_{1: 1}$ are the association constants for the free and included IMQ, respectively and $\mathrm{K}_{\mathrm{A}}$ and $\mathrm{K}_{\mathrm{A}^{\prime}}$ are the inverse of the dissociation constants for the neutral and protonated forms of IMQ, respectively. ${ }^{9}$

$$
\begin{aligned}
& \mathrm{K}_{\mathrm{A}} \\
& \mathrm{IMQ}+\mathrm{H}^{+}+\beta \mathrm{CD} \rightleftarrows \mathrm{IMQ}^{+}+\beta \mathrm{CD} \\
& \mathrm{K}_{1: 1} \uparrow \downarrow \\
& \mathrm{K}_{\mathrm{A}} \\
& \mathrm{IMQ}-\beta \mathrm{CD}+\mathrm{H}^{+} \quad \rightleftarrows \mathrm{IMQ}^{+}-\beta \mathrm{CD}
\end{aligned}
$$

Figure 3. Schematic representation of the association-dissociation equilibrium of the inclusion complex.

In the presence of $\beta C D 16 \mathrm{mM}$, the results showed that IMQ solubility increased 1.7-fold in aqueous solution of citric acid $\mathrm{pH}$ 3.0. An increase of 2.2 and 2.7-fold in the drug solubility was observed in acetate buffer $\mathrm{pH} 5.6$ and phosphate buffer $\mathrm{pH} 7.4$, respectively. The lower increment on IMQ solubility in aqueous solution of citric acid $\mathrm{pH} 3.0$ can be ascribed to the increase in the solubility of the free drug which was higher than in the other media. The apparent stability constant values can be evaluated considering the presence of the neutral drug and its protonated form in solution. The ionization increases drug solubility and it is accompanied by a decrease on $\mathrm{K}_{1: 1}$ value. This reduction is generally compensated by an increase of drug solubility and consequently the complexation efficiency increases. ${ }^{28}$ This trend was observed for $\beta C D$ :IMQ complex. In acidic media, IMQ is protonated and its affinity for cyclodextrin cavity decreases, followed by a decrease in the $\mathrm{K}_{1: 1}$ value in aqueous solution of citric acid $\mathrm{pH}$ 3.0. In contrast, the complexation efficiency in the same solution increased when compared to the two others.

Argenziano et al. ${ }^{1}$ investigated IMQ inclusion complexes prepared with (2-hydroxy) propyl $\beta$-cyclodextrin (HP $\beta C D$ ) and carboxymethyl $\beta$-cyclodextrin $(\mathrm{CM} \beta \mathrm{CD})$. For phase solubility studies, IMQ was suspended in a water solution containing an equimolar amount of HP $\beta C D$ or $C M \beta C D$. The results showed a higher complexation capability for $\mathrm{CM} \beta \mathrm{CD}\left(10,552.2 \mathrm{M}^{-1}\right)$ in comparison to $\mathrm{HP} \beta \mathrm{CD}$ (779.8 $\mathrm{M}^{-1}$ ). Additionally, CM $\beta C D$ solubility isotherm showed an $A_{p}$ type curve suggesting the formation of higher-order complexes other than 1:1 complex. The C.E. was 0.01 and 1.25 for $\mathrm{HP} \beta C D$ and $C M \beta C D$, respectively. Similarly, Ramineni et al. ${ }^{29}$ evaluated IMQ solubility in the presence of HP $\beta C D$. The apparent stability constant obtained for the HP $\beta C D$ :IMQ complex was $23.3 \pm 1.8 \mathrm{M}^{-1}$ and the maximum solubility of the inclusion complex was $100 \pm 5 \mu \mathrm{g} \mathrm{mL}{ }^{-1}$. In another study, IMQ solubility was evaluated in different solvents and pharmaceutical excipients. The results showed that IMQ highest solubility was in oleic acid while its solubility was lower than $1 \mathrm{mg} \mathrm{mL}^{-1}$ in $\beta C D .{ }^{30}$ During the development of this research, $\mathrm{HP} \beta C D$, methyl- $\beta$-cyclodextrin $(\mathrm{M} \beta \mathrm{CD})$ and the natural cyclodextrins, $\alpha \mathrm{CD}$ and $\gamma \mathrm{CD}$, were tested as solubilizing agent for IMQ. However, the amount of ethanol needed to prepare the inclusion complex with $\mathrm{HP} \beta C \mathrm{C}$ and $\mathrm{M} \beta \mathrm{CD}$, and the low solubility of IMQ in $\alpha \mathrm{CD}$ and $\gamma \mathrm{CD}$ made these alternatives unviable; due to these limitations the study was carried out only with $\beta C D$ in different $\mathrm{pH}$ conditions. The apparent stability constant values of $\beta C D$ complexes with different drugs should vary from 50 to $2000 \mathrm{M}^{-1}$ for biological applications. ${ }^{31}$ Even though an increase in IMQ aqueous solubility was observed in the presence of $\beta C D$, this formulation approach did not sufficiently increased IMQ solubility to achieve a final product concentration of 5\% (i.e., $5 \mathrm{mg}$ in $100 \mathrm{mg}$, as in Aldara, the commercial product).

\section{Determination of complex stoichiometry}

The stoichiometry of the $\beta C D$ :IMQ complex was confirmed by the method of continuous variation (Job's 
plot) where solutions of $\beta C D$ and IMQ at equimolar concentration $(0.03 \mathrm{mM})$ in aqueous solution of citric acid pH 3.0 were assayed by UV-Vis absorption spectroscopy at $25^{\circ} \mathrm{C}$. The Job's plot showed that the maximum was reached for IMQ molar fraction, $\mathrm{R}=0.5$, indicating that the complex stoichiometry is 1:1 (see Figure $\mathrm{S} 1$ in Supplementary Information (SI) section).

\section{${ }^{1} \mathrm{H}$ NMR analyses}

The formation of inclusion complex was investigated in water/solvent by NMR spectroscopy, since this technique provides direct and detailed information on the physicochemical interactions between host and guest..$^{32}$ IMQ and $\beta C D$ structures are shown in Figure 1 with the numbering systems used to ${ }^{1} \mathrm{H}$ assignment.

Hydrogens of IMQ aromatic ring were assigned based on COSY spectral data (data not shown). The resonance shift data of the compounds are reported in Table 2. The data evidenced that IMQ presence induces upfield changes in the ${ }^{1} \mathrm{H}$ NMR chemical shift values for both protons, H3 and $\mathrm{H} 5$, which are located inside the $\beta \mathrm{CD}$ cavity. These protons showed an upfield shift due to the shielding effect exerted by the guest molecule. In contrast to $\mathrm{H} 3$ and H5 protons, the protons located on the outer surface of $\beta C D$ $(\mathrm{H} 1, \mathrm{H} 2, \mathrm{H} 4$ and $\mathrm{H} 6)$ showed negligible changes in their chemical shift. Greatbanks et al. ${ }^{33}$ observed that when $\Delta \delta \mathrm{H} 3>\mathrm{H} 5$ the guest molecule is partially inserted in the cyclodextrin cavity. On the other hand, when $\Delta \delta \mathrm{H} 3 \leq \mathrm{H} 5$ the guest molecule is deeply inserted in the cyclodextrin cavity. Except for proton Hd, all IMQ protons showed changes in their chemical shift. The signals of $\mathrm{He}, \mathrm{Hf}$ and $\mathrm{Hg}$ protons displayed high upfield frequency changes, while the resonance of the aromatic protons and the methyl groups moved downfield. From the results, it is reasonable to postulate that the isobutyl moiety (containing protons $\mathrm{Hf}, \mathrm{Hg}$ and $\mathrm{Hh}$ ) and the imidazole ring (containing proton $\mathrm{He})$ must be inside the lipophilic core of $\beta C D$. Therefore, the results of the NMR experiments provided clear demonstration that IMQ is entrapped inside $\beta C D$ cavity through the hydrophobic portion of the molecule. The protonated group, $-\mathrm{NH}_{3}{ }^{+}$, is close to $\beta \mathrm{CD}$ wider rim or exposed outside the cavity.

ROESY NMR technique has the unique ability to provide detailed information on molecular geometry. ${ }^{34}$ The technique determines through-space magnetic interactions that give rise to the nuclear Overhauser effect (NOE) ${ }^{34}$ NOE effect is a common phenomenon observed in NMR spectroscopy which consists in the transfer of the spin polarization from one population of nuclear spins to another, occurring between atoms that are separated
Table 2. ${ }^{1} \mathrm{H}$ NMR chemical shift of $\beta C D$, IMQ and CA hydrogens in $\mathrm{D}_{2} \mathrm{O}$ or DMSO- $d_{6}$ at $25^{\circ} \mathrm{C}, 400 \mathrm{MHz}$

\begin{tabular}{|c|c|c|c|}
\hline${ }^{1} \mathrm{H}$ & $\delta_{\text {free }}^{\mathrm{a}} / \mathrm{ppm}$ & $\delta_{\text {bound }}^{\mathrm{a}} / \mathrm{ppm}$ & $\Delta^{\mathrm{b}} / \mathrm{ppm}$ \\
\hline \multicolumn{4}{|c|}{$\beta$-Cyclodextrin } \\
\hline H1 & 5.024 & 5.015 & -0.009 \\
\hline H3 & 3.919 & 3.874 & -0.045 \\
\hline H6 & 3.832 & 3.826 & -0.006 \\
\hline H5 & 3.808 & 3.785 & -0.023 \\
\hline $\mathrm{H} 2$ & 3.604 & 3.601 & -0.003 \\
\hline H4 & 3.538 & 3.528 & -0.010 \\
\hline \multicolumn{4}{|c|}{ Imiquimod } \\
\hline $\mathrm{He}$ & 8.172 & 8.096 & -0.076 \\
\hline $\mathrm{Hd}$ & 8.000 & 7.992 & -0.008 \\
\hline $\mathrm{Ha}$ & 7.614 & 7.678 & 0.063 \\
\hline $\mathrm{Hb}$ & 7.434 & 7.744 & 0.310 \\
\hline $\mathrm{Hc}$ & 7.264 & 7.632 & 0.368 \\
\hline $\mathrm{NH}_{2}$ & 6.561 & $\mathrm{nd}^{\mathrm{c}}$ & - \\
\hline $\mathrm{Hf}$ & 4.399 & 4.352 & -0.048 \\
\hline $\mathrm{Hg}$ & 2.177 & 2.154 & -0.022 \\
\hline $\mathrm{Hh}$ & 0.919 & 0.941 & 0.021 \\
\hline \multicolumn{4}{|c|}{ Citric acid } \\
\hline $\mathrm{Hi}$ & 2.988 & 2.829 & -0.159 \\
\hline $\mathrm{Hj}$ & 2.809 & 2.728 & -0.082 \\
\hline
\end{tabular}

${ }^{\mathrm{a}} \delta$ : chemical shift; ${ }^{\mathrm{b}} \Delta=\delta_{\text {bound }}-\delta_{\text {free }} ;{ }^{\mathrm{c}}$ nd: not detected.

in space by less than $5 \AA{ }^{35,36}$ The inter-atomic distances derived from the observed NOE are particularly useful to determine molecular geometry. ${ }^{35}$ ROESY technique is preferred in the study of mid-sized molecules, such as peptides, oligosaccharides and host-guest complexes because this type of molecules exhibit non-zero and positive NOE in ROESY experiments. ${ }^{34}$ In the case of $\beta C D$ :IMQ inclusion complex, NOE-based experiments were done in one dimension (1D) because its sensibility is higher than the two-dimension (2D) experiments which was necessary due to the weak NOE interactions and poor aqueous solubility of the inclusion complex. It was irradiated $\beta C D$ protons $\mathrm{H} 3$ and $\mathrm{H} 5$, protons of the imidazole (He), quinoline (Ha, $\mathrm{Hb}, \mathrm{Hc}$ and $\mathrm{Hd}$ ) and isobutyl ( $\mathrm{Hf}, \mathrm{Hg}$ and $\mathrm{Hh}$ ) groups of IMQ. The internuclear correlations are shown in Figure 4. Protons were assigned according to the numbering given in Figure 1.

Figure $4 \mathrm{a}$ shows correlations between protons $\mathrm{H} 3$ from $\beta C D$ with protons $\mathrm{Hc}, \mathrm{Hd}, \mathrm{He}$ and the methyl groups $(\mathrm{Hh})$ of IMQ. On the other hand, the 1D-ROESY spectrum of $\mathrm{H} 5$ protons of $\beta C D$ (Figure $4 \mathrm{~b}$ ) shows only correlation between these protons with the methyl groups (Hh) of IMQ. The results also showed correlation between proton $\mathrm{He}$ of 
IMQ and protons $\mathrm{H} 3$ located in the interior cavity of $\beta \mathrm{CD}$ (Figure 4c). It is interesting to observe that only protons $\mathrm{Hd}$ and $\mathrm{Hc}$ of the quinoline group interact with protons $\mathrm{H} 3$ (Figures S2a and S2b in SI section). Correlations between protons $\mathrm{Hb}$ and $\mathrm{Ha}$ of the quinoline group with protons H3 and H5 were not observed (Figures S2c and S3a in SI section). On 1D-ROESY spectrum of the IMQ methyl groups (Hh), it can be observed correlation between these groups with protons $\mathrm{H} 3$ and $\mathrm{H} 5$ of the interior cavity of $\beta \mathrm{CD}$ (Figure S3b in SI section). The 1D-ROESY experiments also provided another relevant result to understand the dynamics of the inclusion complex formation. The irradiation of the citric acid protons, $\mathrm{Hi}$ and $\mathrm{Hj}$ (Figure S3c in SI section), showed no interaction between these protons with protons $\mathrm{H} 3$ and $\mathrm{H} 5$ located in the interior of the $\beta \mathrm{CD}$ cavity suggesting that this compound does not compete with IMQ for $\beta C D$ cavity. However, changes in the chemical shifts of protons $\mathrm{Hi}$ and $\mathrm{Hj}$ observed in DOSY NMR experiments suggest interaction between citric acid protons and the inclusion complex, but the nature of this interaction is uncertain.

1D-ROESY experiments gave evidence that the isobutyl moiety (containing protons $\mathrm{Hf}, \mathrm{Hg}$ and $\mathrm{Hh}$ ) and the imidazole ring (containing proton He) of IMQ must be
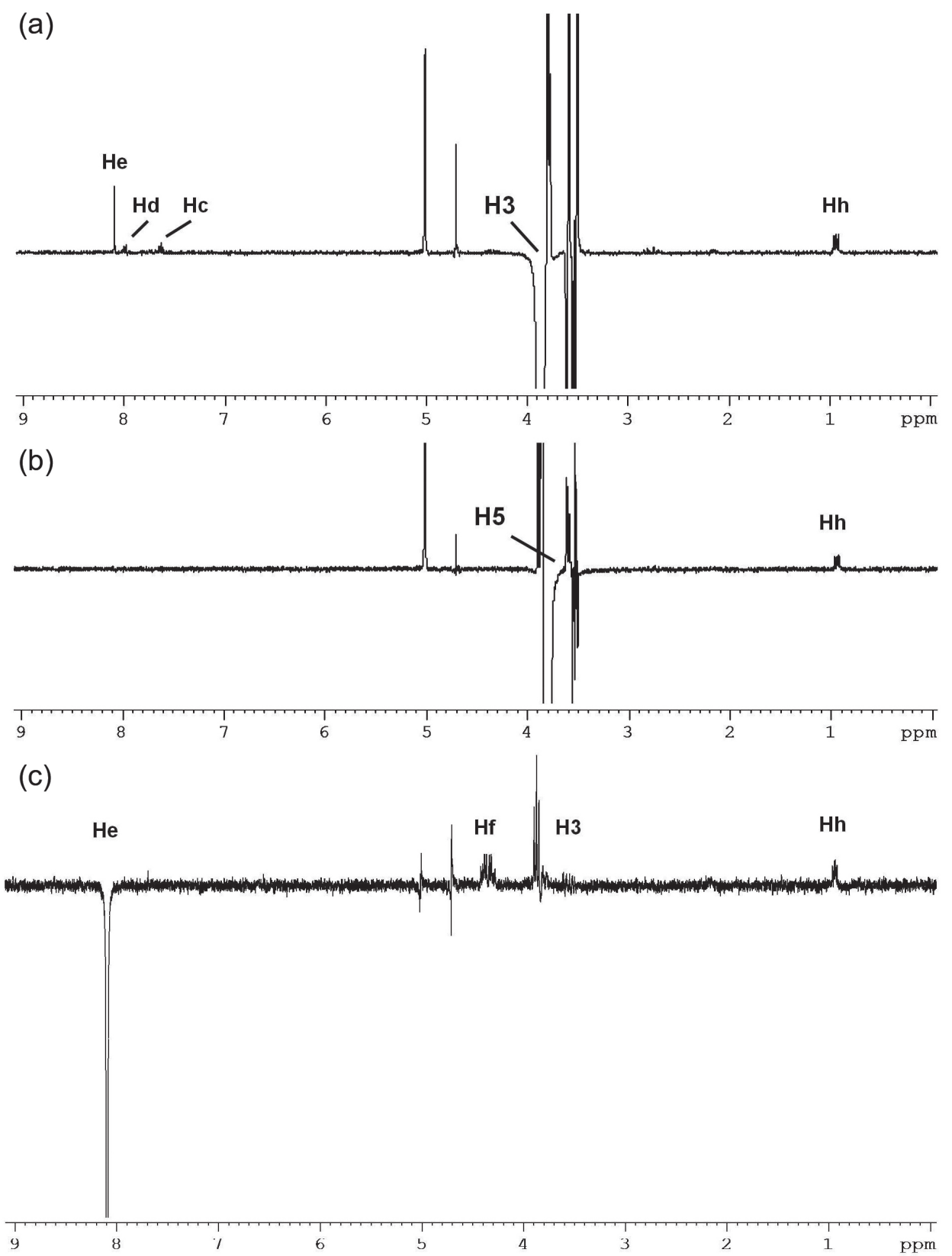

Figure 4. 1D-ROESY spectra of the $\beta C D$ :IMQ complex (concentration $26 \mathrm{mM}$ ) in $\mathrm{D}_{2} \mathrm{O}$ at $25^{\circ} \mathrm{C}$. Selective pulse at (a) protons $\mathrm{H} 3$ of $\beta C D$, (b) protons $\mathrm{H} 5$ of $\beta \mathrm{CD}$ and (c) protons He of IMQ. 
inside the lipophilic core of $\beta C D$. Therefore, the results provided clear demonstration that IMQ is embedded into the $\beta C D$ cavity to form an inclusion complex. The protonated group, $-\mathrm{NH}^{+}$, is close to $\beta \mathrm{CD}$ wider rim or exposed outside the cavity. It is important to point out that correlations between protons $\mathrm{Ha}$ and $\mathrm{Hb}$ from IMQ with protons $\mathrm{H} 3$ and $\mathrm{H} 5$ located inside $\beta \mathrm{CD}$ cavity were not observed which suggest that IMQ quinoline group was not oriented towards $\beta C D$ inner rim on the formation of the inclusion complex.

It has been reported in the literature ${ }^{37-39}$ that low molecular weight hydroxyacids such as ascorbic, maleic, L-tartaric and citric acid interact with a basic function of the guest molecule and with the hydroxyl group of the $\mathrm{CD}$. The hydroxyacids do not fit into the CD cavity, but remain outside. The mechanism of action of these hydroxyacids is through electrostatic interactions between oppositely charged compounds, the guest molecule and the hydroxyacid, at one end and the stabilization of the inclusion complex through the formation of hydrogen bonds between the hydroxyacids and the hydroxyl group of the CD on the other end. ${ }^{7}$ Dua et al. ${ }^{40}$ studied the formation of Norfloxacin/ $\beta C D$ inclusion complex with the addition of ascorbic acid. The mechanism proposed that electrostatic interactions take place between the polar hydroxyl groups of ascorbic acid and the polarizable group of Norfloxacin. It was also considered that hydrogen bonding and solvation energy play a significant role in the formation of Norfloxacin/ $\beta C D$ inclusion complex. The authors observed an enhancement in the Norfloxacin solubility which was attributed to changes in the $\mathrm{pH}$ of the immediate microenvironment of the drug molecule with the addition of ascorbic acid as solubilizing agent.

DOSY technique is often used in the study of the inclusion complex dynamic. This technique is based on the determination of the diffusion coefficients of the guest in the absence and presence of the complexation agent. The diffusion coefficients are used to calculate the fraction of the complexed guest and the apparent stability constant $\left(\mathrm{K}_{1: 1}\right)$ of the complex formed..$^{41}$ The diffusion coefficients of individual components and in the presence of increasing concentration of $\beta C D$ are in Table 3. The value of the diffusion coefficient is the average of the coefficients obtained in the experiment. IMQ, $\beta C D, C A$ and water showed distinct coefficients. Those values agree with the size of the molecules present in solution whose coefficient and structural properties are interrelated due to the dependency of the diffusion coefficient to the geometry and the size of the molecule. ${ }^{42}$ The results showed that the diffusion coefficient of IMQ decreased gradually as the concentration of $\beta C D$ increased even though it was not reduced to the diffusion coefficient of $\beta C D$. It is important to notice that there was a slightly change in the diffusion coefficient of $\beta C D$ as well as in the water diffusion coefficient.

The reduction of IMQ diffusion coefficient in the presence of $\beta C D$ showed that the diffusion coefficients are sensitive to the association phenomenon and the results suggested that there was interaction between $\beta C D$ and IMQ. The same reasoning can be applied to CA where the results also demonstrated that it interacted with the inclusion complex due to the reduction of its diffusion coefficient. However, it was not possible to determine the type of interaction. Kurkov and Loftsson ${ }^{7}$ suggest that the interactions between $\mathrm{CA}$ and the inclusion complex involve ion pair formation between CA and IMQ and interaction with $\beta C D$ through the formation of hydrogen bonds with the hydroxyl groups located at the rim of $\beta C D$. The apparent stability constant $\left(\mathrm{K}_{1: 1}\right)$ determined by this technique was $66.30 \pm 7.07 \mathrm{M}^{-1}$. The relativity low value of $\mathrm{K}_{1: 1}$ indicated weak interaction between $\beta C D$ and IMQ. Similar result was observed in the phase solubility studies where the $\mathrm{K}_{1: 1}$ in aqueous solution of citric acid pH 3.0 was $50.66 \pm 1.13 \mathrm{M}^{-1}$. Both results suggested that the inclusion complex has low thermodynamic stability.

\section{Differential scanning calorimetry (DSC)}

DSC is a powerful analytical tool for the physicochemical characterization of inclusion complexes,

Table 3. Concentration of $\beta C D$, diffusion coefficients (D) of IMQ, CA, $\beta C D$ and water, and the fraction (x) of IMQ present in the complex

\begin{tabular}{lccccc}
\hline$[\beta \mathrm{CD}] / \mathrm{mM}$ & $\mathrm{D}_{(\mathrm{IMQ})} /\left(\times 10^{-10} \mathrm{~m}^{2} \mathrm{~s}^{-1}\right)$ & $\mathrm{D}_{(\mathrm{CA})} /\left(\times 10^{-10} \mathrm{~m}^{2} \mathrm{~s}^{-1}\right)$ & $\mathrm{D}_{(\beta \mathrm{CD})} /\left(\times 10^{-10} \mathrm{~m}^{2} \mathrm{~s}^{-1}\right)$ & $\mathrm{D}_{(\mathrm{HOD})} /\left(\times 10^{-10} \mathrm{~m}^{2} \mathrm{~s}^{-1}\right)$ & $\mathrm{x}_{(\beta \mathrm{CD}: \mathrm{IMQ})} / \%$ \\
\hline 0 & $5.342( \pm 0.027)$ & $6.132( \pm 0.003)$ & - & 23.851 & - \\
4 & $4.879( \pm 0.052)$ & $6.113( \pm 0.014)$ & $2.864( \pm 0.020)$ & 23.391 & $18.69( \pm 0.01)$ \\
8 & $4.742( \pm 0.256)$ & $6.089( \pm 0.009)$ & $2.900( \pm 0.017)$ & 23.585 & $24.22( \pm 0.09)$ \\
12 & $4.656( \pm 0.034)$ & $5.921( \pm 0.010)$ & $2.855( \pm 0.015)$ & 23.282 & $27.59(<0.01)$ \\
16 & $4.454( \pm 0.062)$ & $5.853( \pm 0.010)$ & $2.872( \pm 0.016)$ & 23.635 & $35.96( \pm 0.02)$ \\
16 & - & - & $2.856( \pm 0.015)$ & 23.573 & - \\
\hline
\end{tabular}

$\beta$ CD: $\beta$-cyclodextrin; IMQ: imiquimod; CA: citric acid; HOD: deuterium oxide. 
especially when it is coupled with a complementary technique such as PXRD. ${ }^{32}$ The DSC curves revealed marked structural differences between pure components, the physical mixtures and the inclusion complex. The DSC curve of CA alone showed a melting endotherm at $153{ }^{\circ} \mathrm{C}$. The thermal curve of IMQ exhibited a typical sharp melting endotherm at $298{ }^{\circ} \mathrm{C}$ indicative of its anhydrous and crystalline state, while pure $\beta C D$ showed two endotherm effects corresponding to its dehydration $\left(166^{\circ} \mathrm{C}\right)$ and degradation $\left(302{ }^{\circ} \mathrm{C}\right)$, respectively. The DSC curve of $\beta C D$ :IMQ physical mixture consisted of the superimposition of IMQ and $\beta C D$ thermal profiles with no significant changes in the dehydration temperature of $\beta C D$. It was observed a fusion between IMQ melting peak and $\beta C D$ decomposition peak which might be due to the vicinity of the two events. These findings showed that no association takes place when IMQ and $\beta C D$ are simply mixed together.

The thermal curve of CA: $\beta C D$ :IMQ physical mixture showed a reduction in the intensity of the $\mathrm{CA}$ fusion peak $\left(73{ }^{\circ} \mathrm{C}\right)$ and the dehydration peak of $\beta C D\left(183{ }^{\circ} \mathrm{C}\right)$. It was not possible to observe changes in the melting point of IMQ because the experiment had to be interrupted before reaching it. A different pattern was observed in the DSC curve of $\beta C D$ :IMQ complex. The shifting and broadening of CA peak $\left(55^{\circ} \mathrm{C}\right)$ and the very broad dehydration band of $\beta C D$ (from 88 to $158^{\circ} \mathrm{C}$ ) was indicative of a change in the substrate structure. However, this experiment had also to be interrupted before reaching IMQ melting point and no changes in its peak could be observed (thermal curves are depicted in Figure S4 in SI section).

\section{Powder X-ray diffractometry (PXRD)}

PXRD was used to investigate in more depth the differences in the solid state. The diffraction pattern of CA, IMQ and $\beta C D$ showed intense, sharp peaks, indicative of their crystalline nature. The diffraction pattern of CA: $\beta C D$ :IMQ physical mixture corresponded to the superposition of those of the individual components.

Some crystallinity loss was observed in the aforementioned system which can be ascribed to particle size reduction during mixing and dilution of the pure components. ${ }^{20}$ By contrast, the diffraction pattern of the inclusion complex showed a completely diffuse pattern which indicated the formation of a new crystalline phase, suggesting the association of IMQ with $\beta C D$ (PXRD patterns are illustrated in Figure S5 in SI section). It is important to mention that drug amorphization can be a sequence of the lyophilization process or the formation of the inclusion complex. It is possible that X-ray data cannot discriminate between the two events. ${ }^{20}$

\section{Scanning electron microscopy (SEM)}

SEM was employed to analyze the morphological aspects of the inclusion complex. This technique, in conjunction with PXRD, allows observing changes in the morphology of the inclusion complex and provides evidence of the presence of a new solid phase. ${ }^{26}$ Figure 5 illustrates the photomicrographs of IMQ, CA, $\beta C D$, CA: $\beta C D: I M Q$ physical mixture and $\beta C D$ :IMQ complex. The photomicrograph of IMQ (Figure 5a) showed that drug crystals have good definite edges and homogeneous size distribution. Figure 5b showed CA crystal whose form is irregular while the photomicrograph $5 \mathrm{c}$ showed $\beta C D$ crystals whose particles have a wide range of size distribution. Figure 5d showed the photomicrograph of CA: $\beta C D$ :IMQ physical mixture. It can be observed the absence of interaction among the components. On the other hand, a remarkable change in the morphology of the inclusion complex can be observed (Figures 5e and 5f). It can be noted changes in the form and size of the crystals and it is not possible to differentiate the distinctive crystals of the individual components. This new solid phase can be due to the amorphization of the components as a result of complex formation as well as a consequence of the lyophilization process. These observations, in conjunction with the results obtained by DSC and PXRD, can be considered evidence of the formation of the inclusion complex.

\section{Molecular modeling}

IMQ can be included in $\beta C D$ cavity both in the neutral and protonated form $\left(\mathrm{IMQ}^{+}\right)$. Molecular modeling calculations on host-guest interactions were carried out to obtain a better insight into the complex formed between $\beta C D$ and IMQ. Additionally, the appropriate threedimensional representation of $\beta C D$ :IMQ inclusion complex was built taking into account the constrains provided by 1D-ROESY NMR studies. Calculations were performed with the isobutyl moiety of IMQ oriented to the inner rim of $\beta C D$; IMQ quinoline group oriented towards $\beta C D$ inner rim was not considered because 1D-ROESY NMR results did not show interaction between protons $\mathrm{Ha}$ and $\mathrm{Hb}$ from the quinoline group with protons $\mathrm{H} 3$ and $\mathrm{H} 5$ located inside $\beta C D$ cavity. In preliminary calculations, a minimum energy geometry of the inclusion complex with the later orientation was not obtained. The minimum energy structures of $\beta C D$ :IMQ inclusion complex calculated by Gaussian 16 , Revision A. $03^{25}$ are displayed in Figure 6. The binding energy upon complexation was calculated for the minimum energy structures according to equation 2 , where $\mathrm{E}_{(\beta \mathrm{BCD}: \mathrm{IMQ})}$, 

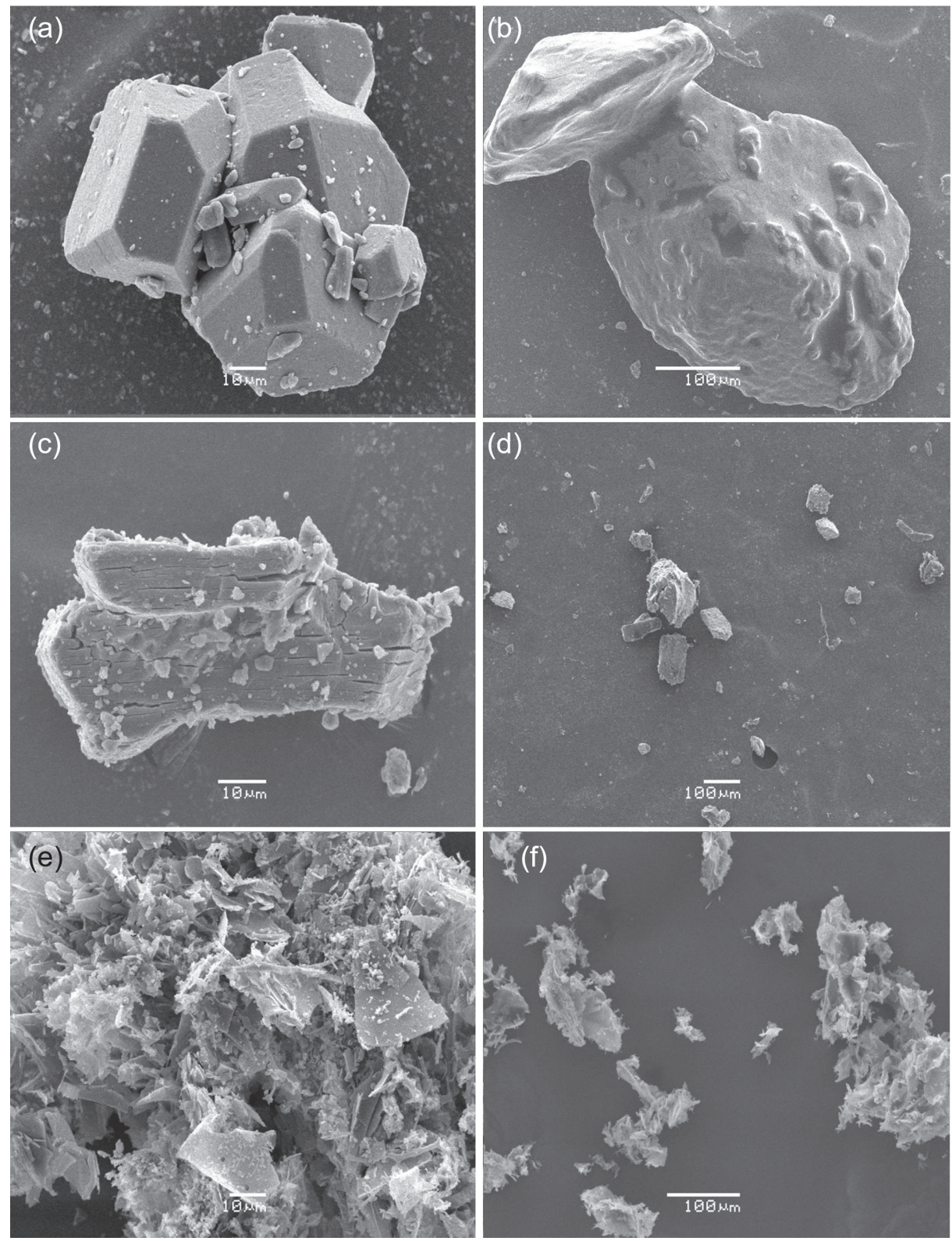

Figure 5. SEM photomicrographs of IMQ (a); CA (b); $\beta C D(c)$; CA: $\beta C D: I M Q$ physical mixture (d); $\beta C D$ :IMQ complex (e and f).

$\mathrm{E}_{(\beta \mathrm{CD}) \mathrm{free}}$ and $\mathrm{E}_{(\mathrm{IMQ}) \text { free }}$ are the total energies of the inclusion complex, the free $\beta C D$ and the free IMQ, respectively. The higher the negative value of the binding energy, the more thermodynamically stable is the inclusion complex. ${ }^{43}$

$$
\mathrm{E}_{\text {binding }}=\mathrm{E}_{(\beta C D: \mathrm{IMQ})}-\left[\mathrm{E}_{(\beta C D) \text { free }}+\mathrm{E}_{(\mathrm{IMQ}) \text { free }}\right]
$$

Molecular modeling confirmed that IMQ was able to form an inclusion complex with $\beta C D$. The binding energy was $89.38 \mathrm{kcal} \mathrm{mol}^{-1}$ for IMQ (Figure 6a) and $100.34 \mathrm{kcal} \mathrm{mol}^{-1}$ for $\mathrm{IMQ}^{+}$(Figure 6b). The positive values for the binding energies indicated the low stability of the inclusion complexes which can be attributed to IMQ orientation inside the $\beta C D$ cavity. From the experimental results, low values for the stability constant was obtained in aqueous solution of citric acid pH 3.0, 50.66 $\pm 1.13 \mathrm{M}^{-1}$ from phase solubility studies and $66.30 \pm 7.07 \mathrm{M}^{-1}$ from NMR experiments. In acidic media, IMQ is protonated and its affinity for cyclodextrin cavity decreases. ${ }^{28}$ In addition, molecular modeling calculations showed that the most favorable configuration of the complexes was the one in which the isobutyl group of IMQ was located inside the $\beta C D$ cavity. These results were supported by those obtained by 1D-ROESY NMR studies.

CA acid was added to $\beta C D$ solution to enhance IMQ aqueous solubility due to the synergic effect between cyclodextrins and hydroxyacids on solubilization of poor basic drugs. ${ }^{14-17}$ The formation of inclusion complex between 
$\beta C D$ and $C A$ was investigated as CA could compete for $\beta C D$ cavity. The binding energy was $134.47 \mathrm{kcal} \mathrm{mol}^{-1}$ for $\mathrm{CA}$ and $132.66 \mathrm{kcal} \mathrm{mol}^{-1}$ for citrate. Molecular modeling suggested that $\beta C D: C A$ inclusion complexes were less stable than $\beta C D$ :IMQ inclusion complexes. It is worth mentioning that 1D-ROESY experiments showed no interaction between citric acid protons with protons $\mathrm{H} 3$ and $\mathrm{H} 5$ located in the interior of $\beta \mathrm{CD}$ cavity.

To elucidate the role of hydrogen bonds, calculations were performed to investigate the hydrogen-bonding interactions between $\beta C D$ and IMQ (Figure 6). The three-dimensional representation of $\beta C D$ :IMQ inclusion complex showed the presence of three intermolecular

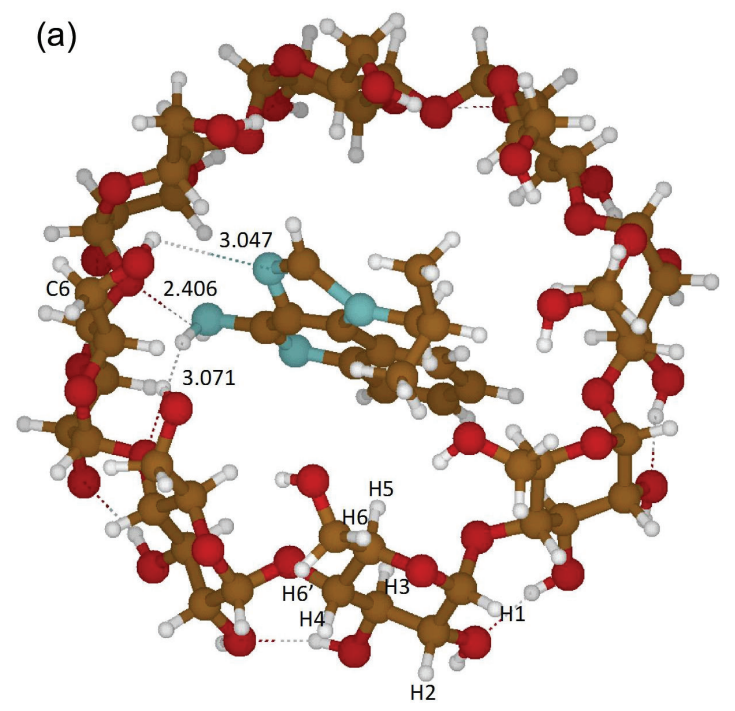

hydrogen bonds: one hydrogen bond between hydrogen of primary hydroxyl group and nitrogen of imidazole group (3.047 $\AA$ ); and two hydrogen bonds between oxygen of $\beta C D$ and hydrogen of $\mathrm{NH}_{2}$ group (2.406 and 3.071 $\AA$ ). As shown in Figure 6b, three hydrogen bonds were identified in the three-dimensional representation for $\mathrm{IMQ}^{+}$where all hydrogen bonds were between oxygen of $\beta C D$ and hydrogen from $\mathrm{NH}_{3}{ }^{+}$group.

Simulated electronic absorption spectra of inclusion complex between $\beta C D$ and $C A$, citrate, IMQ and $\mathrm{IMQ}^{+}$were obtained via TD-DFT calculations coupled with IEF-PCM models (Figure 7a). Calculations were performed by considering the two-layered ONIOM method (Figure 7b). ${ }^{44}$

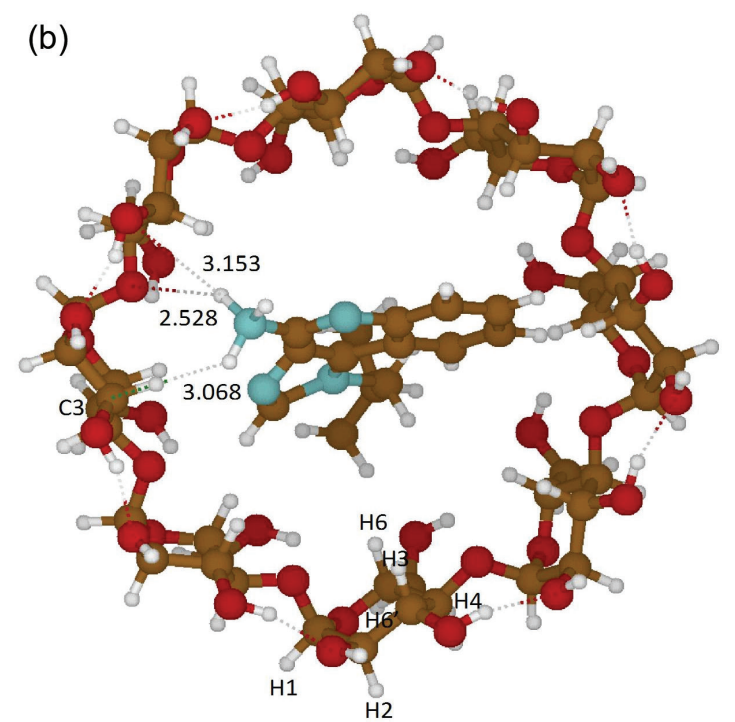

Figure 6. Representation of the inclusion complex between $\beta C D$ and IMQ (a), and its protonated form (b). Inclusion complex representation in (a) from the narrow rim and (b) from the wider rim of $\beta C D$. Hydrogen bonds are indicated by dashed lines. Atom color codes: carbon (brown), hydrogen (white), oxygen (red) and nitrogen (blue).
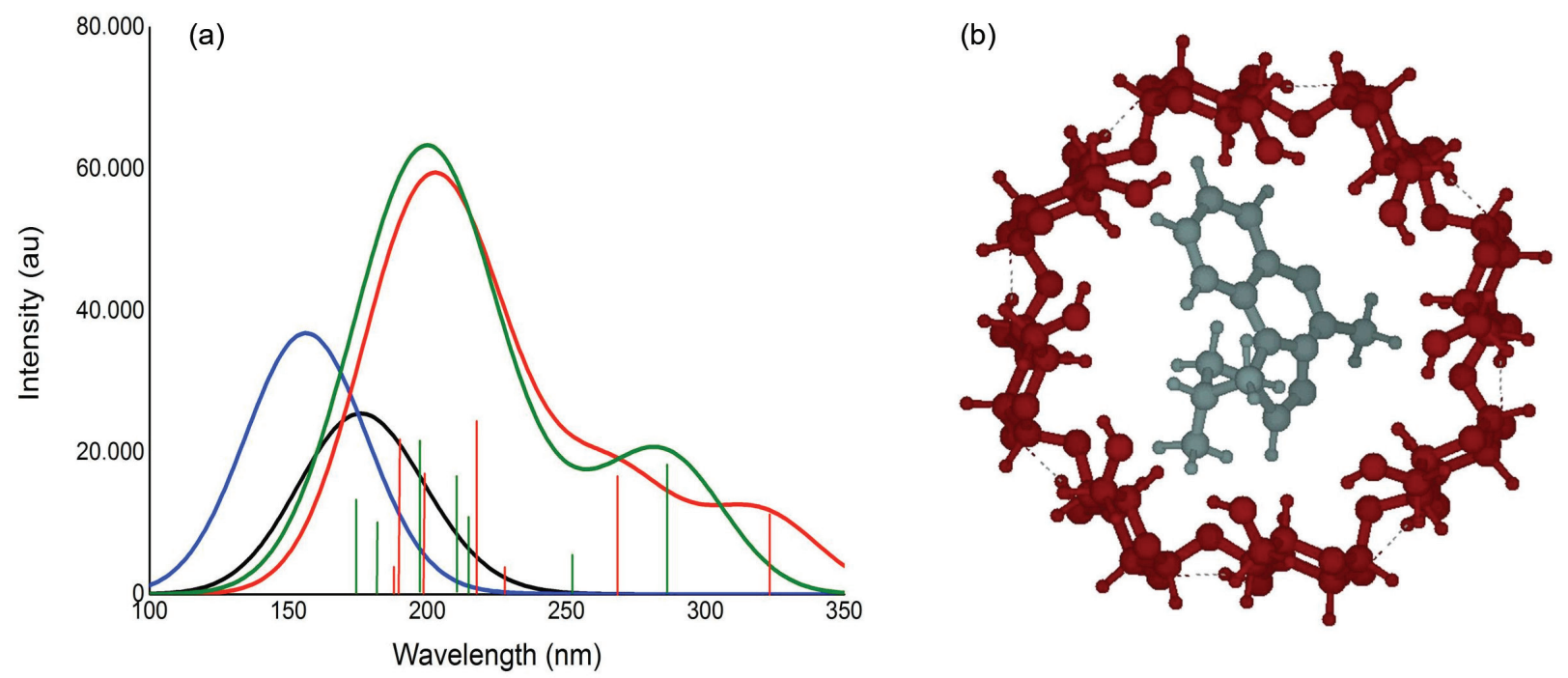

Figure 7. Simulated UV-Vis electronic spectra of $\beta C D$ inclusion complex with CA (blue), citrate (black), IMQ (red) and IMQ (green). Vertical lines represent the relative oscillator strength of each transition (a); The two-layered ONIOM method was employed on calculations. The CAM-B3LYP/6$311++\mathrm{G}(3 \mathrm{df}, 2 \mathrm{p})$ method was used at the high level of theory while $\beta C D$ was described at the low level of theory by PM6 (b). 
Table 4. Thermodynamic parameters for IMQ+, IMQ, $\beta C D$ and the inclusion complexes

\begin{tabular}{|c|c|c|c|c|c|c|c|}
\hline Molecular system & $\mathrm{IC}^{\mathrm{a}}$ & $\mathrm{H} /\left(\mathrm{kJ} \mathrm{mol}^{-1}\right)$ & $\Delta^{\mathrm{b}} \mathrm{H} /\left(\mathrm{kJ} \mathrm{mol}^{-1}\right)$ & $\mathrm{S} /\left(\mathrm{kJ} \mathrm{mol}^{-1}\right)$ & $\Delta^{\mathrm{b}} \mathrm{S} /\left(\mathrm{kJ} \mathrm{mol}^{-1}\right)$ & $\mathrm{G} /\left(\mathrm{kJ} \mathrm{mol}^{-1}\right)$ & $\Delta^{\mathrm{b}} \mathrm{G} /\left(\mathrm{kJ} \mathrm{mol}^{-1}\right)$ \\
\hline $\mathrm{IMQ}^{+}$ & & 769.63 & & 0.53 & & 611.44 & \\
\hline IMQ & & 729.69 & & 0.54 & & 569.65 & \\
\hline$\beta C D(\text { frz })^{c}$ & & $3,439.10$ & & 2.38 & & $2,730.28$ & \\
\hline$\beta C D(f l x)^{d}$ & & $3,445.90$ & & 1.94 & & $2,866.70$ & \\
\hline$\beta C D: \mathrm{IMQ}^{+}(\mathrm{frz})^{\mathrm{c}}$ & 1 & 786.82 & $-3,421.91$ & 0.62 & -2.29 & 602.58 & $-2,739.15$ \\
\hline$\beta C D: I M Q(f r z){ }^{c}$ & 2 & 736.84 & $-3,438.74$ & 0.61 & -1.87 & 555.41 & $-2,744.52$ \\
\hline$\beta C D: \mathrm{IMQ}^{+}(\mathrm{flx})^{\mathrm{d}}$ & 3 & $4,220.06$ & 4.53 & 2.36 & -0.11 & $3,515.43$ & 37.28 \\
\hline$\beta C D: I M Q(f l x)^{d}$ & 4 & $4,180.78$ & 5.19 & 2.26 & -0.22 & $3,508.29$ & 71.94 \\
\hline
\end{tabular}

aC: inclusion complex; ${ }^{\mathrm{b}} \Delta$ : delta; cfrz: the molecular geometry optimization is only on the GUEST molecule (IMQ ${ }^{+}$or IMQ). The HOST molecular geometry was kept frozen (obtained from X-ray diffraction); ${ }^{d}$ flx: full molecular optimization on the system: HOST + GUEST. $\beta C D$ : $\beta$-cyclodextrin; IMQ: imiquimod; H: enthalpy; S: entropy; G: Gibbs free energy.

The theoretical $\lambda_{\max }$ is defined as the wavelength of highest occupied molecular orbital (HOMO)-lowest unoccupied molecular orbital (LUMO) transition; the relative oscillator strength for each transition is represented by vertical lines. The CAM-B3LYP/6-311++G(3df,2p) method described $\mathrm{UV}-\mathrm{Vis}$ spectra of $\beta C D: \mathrm{IMQ}^{+}$inclusion complex with acceptable accuracy; the experimental spectra are shown in Figure S6 in the SI section.

IMQ poor solubility in water prevented the thermodynamic characterization of the inclusion complex by fluorescence spectroscopy. Due to this limitation, the thermodynamic parameters enthalpy $(\Delta \mathrm{H})$, entropy $(\Delta \mathrm{S})$ and Gibbs free energy $(\Delta \mathrm{G})$ were obtained by theoretical calculations (Table 4). Multiple driving forces govern the formation of the inclusion complex which may be exerted simultaneously. ${ }^{9}$ The driving forces include electrostatic interactions, van der Waals contributions, hydrogen bonds, release of conformational strain, exclusion of high energy water from cyclodextrin cavity and charge transfer interactions. ${ }^{9}$ In general, the formation of the inclusion complex is associated with a relatively large negative $\Delta \mathrm{H}$ while $\Delta \mathrm{S}$ can be either positive or negative. ${ }^{9}$ The $\Delta \mathrm{H}$ found for the inclusion complexes 1 and 2 were large negative values. A negative enthalpy indicates the amount of energy released during the formation of the inclusion complex and can be attributed to host-guest interactions through van der Waals forces, hydrophobic interactions, hydrogen bonds and electrostatic interactions. ${ }^{45,46}$ In contrast to the inclusion complexes 1 and 2, the enthalpy values for the inclusion complexes 3 and 4 were positive indicating that the formation of these inclusion complexes was endothermic.

The $\Delta \mathrm{S}$ found for inclusion complexes 1 and 2 were small negative values while a near-zero $\Delta \mathrm{S}$ was found for the inclusion complexes 3 and 4 . Negative entropy usually describe guest molecule that is partially inserted into cyclodextrin cavity or whose movement is restricted due to strong interactions with the host molecule which decrease its degree of freedom. ${ }^{47}$ It should be mentioned that the low entropy value found for $\beta C D$ (flx) molecule was due to the greater packaging of this form when optimized under solvent conditions; $\beta C D$ optimized geometries, $\beta \mathrm{CD}(\mathrm{flx})$ and $\beta C D$ (frz), are depicted in Figure S7 in the SI section. The $\Delta \mathrm{G}$ values give insight on the dissolution conditions that favor the guest molecule solubilization where negative values indicate favorable conditions. ${ }^{48}$ The $\Delta \mathrm{G}$ calculated for the inclusion complexes 1 and 2 were negative indicating that IMQ interaction with $\beta C D$ was spontaneous while the values obtained for the inclusion complexes 3 and 4 were positive. The results showed that the negative $\Delta \mathrm{G}$ values and the stability of the inclusion complexes 1 and 2 were determined by the enthalpy contribution and, therefore, the complexation process was enthalpy-driven whereas the formation of inclusion complexes 3 and 4 was an entropy-driven process.

\section{Conclusions}

The formation of inclusion complex between $\beta C D$ and IMQ was investigated. The inclusion complex was characterized in solution by spectroscopic techniques that provided evidence of the formation of the inclusion complex. NMR technique is of fundamental importance in the characterization of inclusion complexes. It not only provides evidence of the formation of the inclusion complex but also give insight in the geometry and the drug fraction present in the complex.

The apparent stability constants obtained by UVVis absorption spectroscopy and NMR indicated weak interaction between IMQ and $\beta C D$. The values of $K_{1: 1}$ obtained by UV-Vis absorption spectroscopy showed 
that the apparent stability constant in aqueous solution of citric acid pH 3.0 was lower than the values obtained for acetate buffer $\mathrm{pH} 5.6$ and phosphate buffer $\mathrm{pH}$ 7.4. The results demonstrated that the $\mathrm{K}_{1: 1}$ value decreased as the ionization of the drug increased. Remarkably, an increase in the complexation efficiency was observed in aqueous solution of citric acid $\mathrm{pH}$ 3.0. Thus, the decrease in the value of $K_{1: 1}$ was compensated by an increase in the complexation efficiency. The values obtained for the complexation efficiency were extremely low even though the solubility of IMQ increased in aqueous solution of citric acid $\mathrm{pH}$ 3.0. The low values of complexation efficiency can be attributed to IMQ poor aqueous solubility even in the presence of an acidic compound.

NMR experiments provided evidence of the inclusion complex geometry. The results suggested that IMQ was embedded inside $\beta C D$ cavity with the isobutyl moiety oriented to the inner edge of the macromolecule. DOSY results provided the fraction of IMQ present in the complex and showed that IMQ fraction increased with an increase in $\beta C D$ concentration. The results also demonstrated that $C A$ interacted with $\beta C D$ :IMQ complex because it was observed changes in the chemical shift of CA protons. However, it was not possible to determine the type of interaction.

The inclusion complex in the solid state was also assessed by differential scanning calorimetry, powder X-ray diffractometry and scanning electron microscopy. The results of thermal analysis and PXRD suggested the presence of an amorphous structure which can be attributed to the lyophilization of the components and also to the formation of the inclusion complex. Changes in the inclusion complex thermal profile and diffusion pattern were significant when compared to the free components and can be considered as evidence of the formation of the inclusion complex. SEM results showed a significant change in the morphology of the complex when compared to the individual components. Those techniques allowed verify changes in the crystalline structure of the inclusion complex and can be taken as evidence of its formation.

Molecular modeling provided insights into the conformation of the inclusion complex. The results showed that the favorable configuration of the complex was the one in which the isobutyl group of IMQ was inserted inside the cavity of $\beta C D$ which agreed with 1D-ROESY NMR studies. In addition, the theoretical thermodynamic parameters gave insight into the supramolecular forces involved in the formation of the inclusion complex. From the experimental and theoretical results, it is possible to conclude that $\beta C D$ forms an inclusion complex with IMQ; however, the low values of the apparent stability constants suggest a weak interaction which may be attributed to the orientation of IMQ inside $\beta C D$ cavity hampering the use of this approach to improve IMQ aqueous solubility.

\section{Supplementary Information}

Supplementary data are available free of charge at http://jbcs.sbq.org.br as PDF file.

\section{Acknowledgments}

We are grateful to CAPES for the financial support and EMS Sigma Pharma for supplying the imiquimod used in this study.

\section{References}

1. Argenziano, M.; Haimhoffer, A.; Bastiancich, C.; Jicsinszky, L.; Caldera,F.; Trotta, F.; Scutera, S.;Alotto, D.; Fumagalli, M.; Musso, T.; Castagnoli, C.; Cavalli, R.; Pharmaceutics 2019, 11, 138.

2. Bhatta, A. K.; Wang, P.; Keyal, U.; Zhao, Z.; Ji, J.; Zhu, L.; Wang, X.; Zhang, G.; Photodiagn. Photodyn. 2018, 23, 273.

3. Carneiro, R. L.; Poppi, R. J.; Spectrochim. Acta, Part A 2014, $118,215$.

4. van Egmond, S.; Hoedemaker, C.; Sinclair, R.; Int. J. Dermatol. 2007, 46, 318.

5. Chollet, J. L.; Jozwiakowski, M. J.; Phares, K. R.; Reiter, M. J.; Roddy, P. J.; Schultz, H. J.; Ta, Q. V.; Tomai, M. A.; Pharm. Dev. Technol. 1999, 4, 35.

6. Jansook, P.; Ogawa, N.; Loftsson, T.; Int. J. Pharm. 2018, 535, 272.

7. Kurkov, S. V.; Loftsson, T.; Int. J. Pharm. 2013, 453, 167.

8. Loftsson, T.; Brewster, M. E.; J. Pharm. Sci. 2012, 101, 3019.

9. Brewster, M. E.; Loftsson, T.; Adv. Drug Delivery Rev. 2007, 59,645 .

10. Loftsson, T.; Masson, M.; Int. J. Pharm. 2001, 225, 15.

11. Loftsson, T.; Brewster, M. E.; J. Pharm. Sci. 1996, 85, 1017.

12. Zoeller, T.; Dressman, J. B.; Klein, S.; Int. J. Pharm. 2012, 430, 176.

13. Zhang, X.; Zhang, Y.; Zhong, D.; Chen, Y.; Li, S.; Drug Dev. Ind. Pharm. 2007, 33, 163.

14. Mennini, N.; Maestrelli, F.; Cirri, M.; Mura, P.; J. Pharmaceut. Biomed. 2016, 129, 350.

15. Pokharkar, V.; Khanna, A.; Venkatpurwar, V.; Dhar, S.; Mandpe, L.; Acta Pharm. 2009, 59, 121.

16. Barillaro, V.; Bertholet, P.; Hassonville, S. H.; Ziemons, E.; Evrard, B.; Delattre, L.; Piel, G.; J. Pharm. Pharm. Sci. 2004, 7, 378 .

17. Faucci, M. T.; Mura, P.; Drug Dev. Ind. Pharm. 2001, 27, 909.

18. Higuchi, T.; Connors, K. A. In Advances in Analytical Chemistry and Instrumentation, vol. 4; Higuchi, T.; Connors, K. A.; Reill, C. N., eds.; Wiley Interscience: New York, USA, 1965. 
19. Jambhekar, S. S.; Breen, P.; Drug Discovery Today 2016, 21, 356.

20. Badr-Eldin, S. M.; Elkheshen, S. A.; Ghorab, M. M.; Eur. J. Pharm. Biopharm. 2008, 70, 819.

21. Figueiras, A.; Ribeiro, L.; Torres-Labandeira, J. J.; Veiga, F. J. B.; J. Inclusion Phenom. Macrocyclic Chem. 2007, 57, 531.

22. Neacşu, A.; Thermochim. Acta 2018, 661, 51.

23. Anselmi C.; Centini, M.; Maggiore, M.; Gaggelli, N.; Andreassi, M.; Buonocore, A.; Beretta, G.; Facino, R. M.; J. Pharm. Biomed. Anal. 2008, 46, 645.

24. Nilsson, M.; J. Magn. Reson. 2009, 200, 296.

25. Frisch, M. J.; Trucks, G. W.; Schlegel, H. B.; Scuseria, G. E.; Robb, M. A.; Cheeseman, J. R.; Scalmani, G.; Barone, V.; Petersson, G. A.; Nakatsuji, H.; Li, X.; Caricato, M.; Marenich, A. V.; Bloino, J.; Janesko, B. G.; Gomperts, R.; Mennucci, B.; Hratchian, H. P.; Ortiz, J. V.; Izmaylov, A. F.; Sonnenberg, J. L.; Williams-Young, D.; Ding, F.; Lipparini, F.; Egidi, F.; Goings, J.; Peng, B.; Petrone, A.; Henderson, T.; Ranasinghe, D.; Zakrzewski, V. G.; Gao, J.; Rega, N.; Zheng, G.; Liang, W.; Hada, M.; Ehara, M.; Toyota, K.; Fukuda, R.; Hasegawa, J.; Ishida, M.; Nakajima, T.; Honda, Y.; Kitao, O.; Nakai, H.; Vreven, T.; Throssell, K.; Montgomery Jr., J. A.; Peralta, J. E.; Ogliaro, F.; Bearpark, M. J.; Heyd, J. J.; Brothers, E. N.; Kudin, K. N.; Staroverov, V. N.; Keith, T. A.; Kobayashi, R.; Normand, J.; Raghavachari, K.; Rendell, A. P.; Burant, J. C.; Iyengar, S. S.; Tomasi, J.; Cossi, M.; Millam, J. M.; Klene, M.; Adamo, C.; Cammi, R.; Ochterski, J. W.; Martin, R. L.; Morokuma, K.; Farkas, O.; Foresman, J. B.; Fox, D. J.; Gaussian 16, Revision A.03; Gaussian, Inc., Wallingford CT, 2016.

26. Veiga, F.; Pecorelli, C.; Ribeiro, L.; As Ciclodextrinas em Tecnologia Farmacêutica; Minerva: Coimbra, Portugal, 2006.

27. Calsavara, L. P. V.; Zanin, G. M.; Moraes, F. F.; J. Inclusion Phenom. Macrocyclic Chem. 2012, 73, 219.

28. Zia, V.; Rajewski, R. A.; Stella, V. J.; Pharm. Res. 2001, 18, 667.

29. Ramineni, S. K.; Cunningham Jr., L. L.; Dziubla, T. D.; Puleo, D. A.; J. Pharm. Sci. 2013, 102, 593.

30. Telò, I.; Pescina, S.; Padula, C.; Santi, P.; Nicoli, S.; Int. J. Pharm. 2016, 511, 516.
31. Sierpe, R.; Noyong, M.; Simon, U.; Aguayo, D.; Huerta, J.; Kogan, M. J.; Yutronic, N.; Carbohydr. Polym. 2017, 177, 22.

32. Anselmi, C.; Centini, M.; Ricci, M.; Buonocore, A.; Granata, P.; Tsuno, T.; Facino, R. M.; J. Pharm. Biomed. Anal. 2006, 40, 875.

33. Greatbanks, D.; Pickford, R.; Magn. Reson. Chem. 1987, 25, 208.

34. Claridge, T. D. W. In High-Resolution NMR Techniques in Organic Chemistry, vol. 27; Bäckvall, J.-E.; Baldwin, J. E.; Williams, R. M., eds.; Elsevier Ltd.: Amsterdam, The Netherlands, 2009.

35. Mura, P.; J. Pharm. Biomed. Anal. 2014, 101, 238.

36. Folch-Cano, C.; Guerrero, J.; Speisky, H.; Jullian, C.; Olea-Azar, C.; J. Inclusion Phenom. Macrocyclic Chem. 2014, 78, 287.

37. Redenti, E.; Szente, L.; Szejtli, J.; J. Pharm. Sci. 2000, 89, 1.

38. Loftsson, T.; Brewster, M. E.; J. Pharm. Pharmacol. 2010, 62, 1607.

39. Patel, M.; Hirlekar, R.; Asian J. Pharm. Sci. 2019, 14, 104.

40. Dua, K.; Ramana, M. V.; Sara, U. V. S.; Himaja, M.; Agrawal, A.; Garg, V.; Pabreja, K.; Curr. Drug Delivery 2007, 4, 21.

41. Fernandes, A.; Ivanova, G.; Brás, N. F.; Mateus, N.; Ramos, M. J.; Rangel, M.; Freitas, V.; Carbohydr. Polym. 2014, 102, 269.

42. Brand, T.; Cabrita, E. J.; Berger, S.; Prog. Nucl. Magn. Reson. Spectrosc. 2005, 46, 159.

43. Fifere, A.; Marangoci, N.; Maier, S.; Coroaba, A.; Maftei, D.; Pinteala, M.; Beilstein J. Org. Chem. 2012, 8, 2191.

44. Dapprich, S.; Komáromi, I.; Byun, K. S.; Morokuma, K.; Frisch, M. J.; J. Mol. Struct. 1999, 461-462, 1.

45. Passos, J. J.; de Sousa, F. B.; Lula, I. S.; Barreto, E. A.; Lopes, J. F.; de Almeida, W. B.; Sinisterra, R. D.; Int. J. Pharm. 2011, $421,24$.

46. Mura, P.; Faucci, M. T.; Manderioli, A.; Bramanti, G.; J. Inclusion Phenom. Macrocyclic Chem. 2001, 39, 131.

47. Martins, M. H.; Calderini, A.; Pessine, F. B. T.; J. Inclusion Phenom. Macrocyclic Chem. 2012, 74, 109.

48. Hadziabdic, J.; Elezovic, A.; Rahic, O.; Mujezin, I.; Am. J. Anal. Chem. 2012, 3, 811.

Submitted: December 16, 2019 Published online: April 3, 2020 